\title{
Effect of web openings on the structural behavior of RC beams subjected to pure torsion
}

\author{
Taha Abdo ${ }^{1}$, Rasha Mabrouk ${ }^{1, *}$ \\ ${ }^{1}$ Faculty of Engineering, Cairo University, Giza, Egypt
}

\begin{abstract}
In the construction of modern buildings, the presence of openings became a necessity nowadays in order to accommodate the many pipes and ducts required for the different services. On the other hand, the presence of these openings in RC beams affects their structural behavior. One important behavior that needs further study would be torsion. Currently, there are no guide lines available to analyze or design RC beams with web openings under pure torsion. Thus, the main objective of this research is to investigate the behavior of simply supported RC beams with openings subjected to pure torsion. In the first part of this paper, an experimental study is conducted on seven beams subjected to pure torsion loading in order to investigate the effect of the number of openings, the spacing between stirrups, and beam depth. All beams have a constant clear span length of $1800 \mathrm{~mm}$ and a constant beam width of $150 \mathrm{~mm}$. The beams have varying opening number and stirrups arrangement as well as varying beam depth in order to investigate the effect of these parameters on the behavior of the beams. Systematic measurements such as the cracking torque, the ultimate torque, the angle of rotation of the beam at cracking, and the angle of rotation of the beam at the ultimate load are conducted for further understanding of the beam behavior under torsion. In the second part of the paper, the experimental results are compared with the numerical results obtained using the non-linear finite element analysis program, ANSYS. Good agreement between the experimental and numerical results is found.
\end{abstract}

\section{Introduction}

In most buildings, utility pipes and ducts are accommodated in the space within the floor ceiling sandwich. Passing these pipes and ducts through transverse openings in the floor beams saves a significant amount of headroom and results in a more compact design. In multistory buildings, the total height can be reduced due to presence of the transfer openings that allow the passage of pipes and ducts through it [1]. The presence of transverse openings will transform the simple beam behavior into a more complex behavior. Currently, there are no recommendations for analyzing or designing reinforced concrete beams with web openings subjected to pure torsion in the design codes. Some standard methods for design are available but much work is still needed.

* Corresponding author: yrasha@yahoo.com 
There are previous studies conducted such as those done by Mansur, et al. [2] which studies reinforced concrete beams with large rectangular openings under pure torsion where the opening sizes and their locations were varied. Also, there is the research carried out by Elbadawy [3] to study the effect of the opening dimensions, beam width, and the presence of the vertical stirrups on the structural behavior of beam with opening under torsion. Akhtaruzzaman [5] and Mansur and Tan [6] developed equations to calculate the torsional moment resistance of reinforced concrete beams with rectangular and circular opening. Fawzy [7] studied the use of externally bonded fiber reinforced polymers to strengthen concrete beams with a large web opening subjected to pure torsion. Venugopal M. [8] studied the behavior of GFRP retrofitted rectangular RC beams with small web openings under torsion.

The design codes such as ACI 318-08 [9] and ECP-203-2007 [10] do not give any explicit guidance for designing these elements with openings. The main objectives of this research is to study the effect of openings on the structural behavior of beams subjected to pure torsion in an attempt to obtains some specific guidelines to help structural engineers when dealing with this problem. The research is divided into two parts; an experimental part and as analytical part as shown below.

\section{Experimental program}

Table 1 shows the details of the seven beam specimens tested in this research. All the test samples had an overall span of $2000 \mathrm{~mm}$ and width of $150 \mathrm{~mm}$. As shown in Figure 1, the overall length of $2000 \mathrm{~mm}$ was divided into three parts; the middle part was $1600 \mathrm{~mm}$ which was the test zone. The two end parts were $200 \mathrm{~mm}$ each, and heavily reinforced to be safe against failure during testing. Three parameters were studied namely; the effect of the number of openings $(\mathrm{N})$, the effect of spacing between stirrups $(\mathrm{S})$ and the effect of the beam height $(\mathrm{H})$. Figure 2 and Figure 3 show the details of all the beams under study.

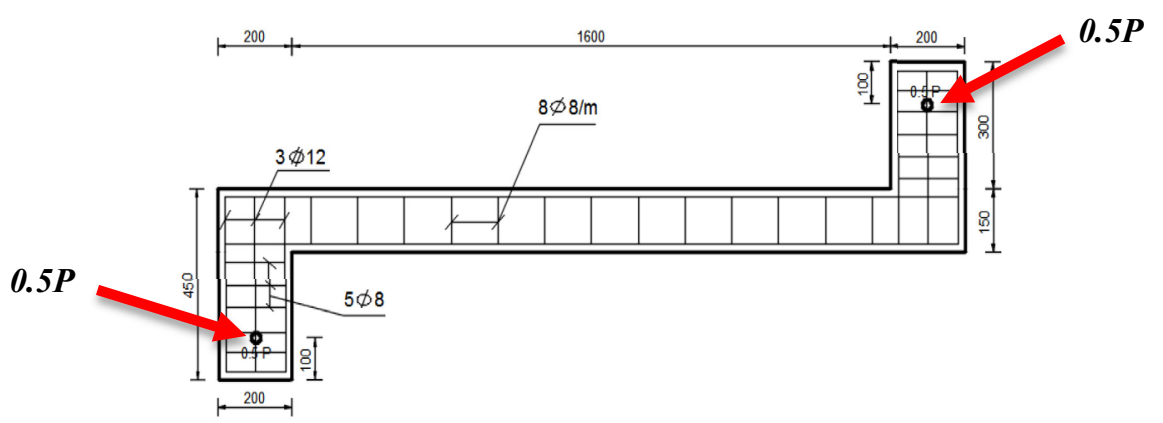

Fig. 1. General plan of the beams under study.

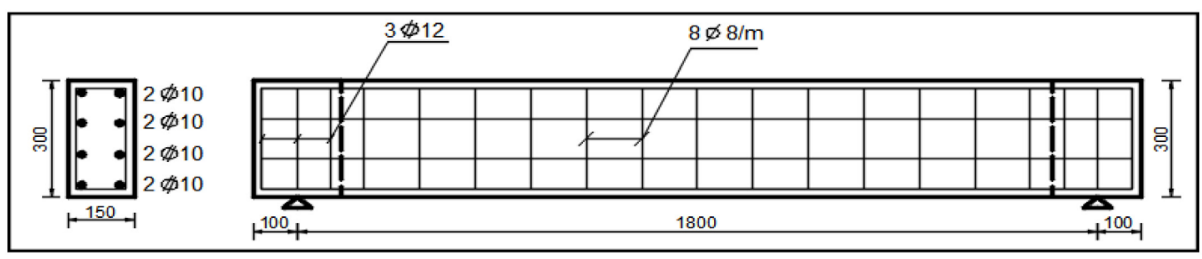

Fig. 2. Dimensions and reinforcement details of the control beam B1 (N0-S125-H300). 

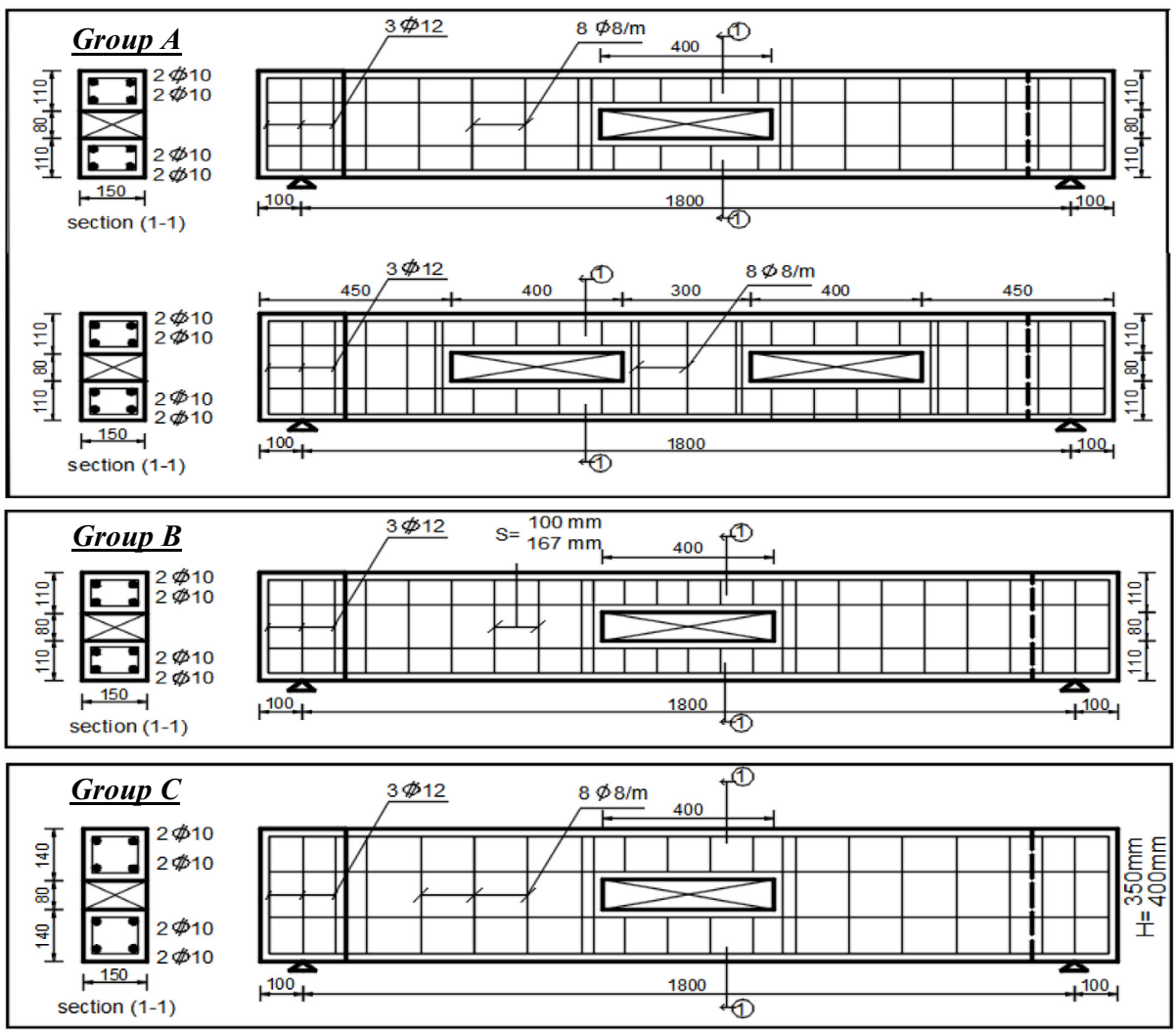

Fig. 3. Dimensions and reinforcement details of the tested specimens with openings.

Table 1. Outline of the experimental program

\begin{tabular}{|c|c|c|c|c|c|c|c|c|}
\hline \multirow{2}{*}{ ڤે } & \multirow{2}{*}{ ڤ్లే } & \multirow[b]{2}{*}{ Notation } & \multirow{2}{*}{$\begin{array}{l}\text { Studied } \\
\text { Parameter }\end{array}$} & \multicolumn{3}{|c|}{ Opening Variable } & \multirow{2}{*}{$\begin{array}{l}\text { Longitudinal } \\
\text { Reinforcement }\end{array}$} & \multirow{2}{*}{ Stirrups } \\
\hline & & & & $\mathrm{N}$ & $\begin{array}{c}\mathrm{S} \\
(\mathrm{mm})\end{array}$ & $\begin{array}{c}\mathrm{H} \\
(\mathrm{mm})\end{array}$ & & \\
\hline & B1 & N0-S125-H300 & $\begin{array}{l}\text { Control } \\
\text { Beam }\end{array}$ & 0 & 125 & 300 & $8 \phi_{10}$ & $8 \varnothing 8 / \mathrm{m}$ \\
\hline \multirow{2}{*}{$\mathbf{A}$} & B2 & N1-S125-H300 & \multirow{2}{*}{$\begin{array}{l}\text { Number of } \\
\text { openings } \\
\text { (N) }\end{array}$} & 1 & 125 & 300 & $8 \not 10$ & $8 \varnothing 8 / \mathrm{m}$ \\
\hline & B3 & N2-S125-H300 & & 2 & 125 & 300 & $8 \phi_{10}$ & $8 \varnothing 8 / \mathrm{m}$ \\
\hline \multirow{2}{*}{ B } & B4 & N1-S100-H300 & \multirow{2}{*}{$\begin{array}{c}\text { Spacing } \\
\text { between } \\
\text { stirrups (S) }\end{array}$} & 1 & 100 & 300 & $8 \phi_{10}$ & $10 \varnothing 8 / \mathrm{m}$ \\
\hline & B5 & N1-S165-H300 & & 1 & 167 & 300 & $8 \phi_{10}$ & $6 \varnothing 8 / \mathrm{m}$ \\
\hline \multirow{2}{*}{$\mathbf{C}$} & B6 & N1-S125-H350 & \multirow{2}{*}{$\begin{array}{c}\text { Beam } \\
\text { Height }(H)\end{array}$} & 1 & 125 & 350 & $8 \phi_{10}$ & $8 \varnothing 8 / \mathrm{m}$ \\
\hline & B7 & N1-S125-H400 & & 1 & 125 & 400 & ${ }_{8} \phi_{10}$ & $8 \varnothing 8 / \mathrm{m}$ \\
\hline
\end{tabular}

\subsection{Materials used}

Normal strength concrete using local materials was used in casting all the specimens. The concrete mixture was designed for a characteristic compressive strength of $30 \mathrm{MPa}$ after 28 days. The concrete mix consisted of $350 \mathrm{~kg}$ cement, 175 liter of water, $1250 \mathrm{~kg}$ of coarse aggregate, $650 \mathrm{~kg}$ fine aggregate, and 3.5 liter of B.V.F admixture. The form work was 
removed after 72 hours from casting. All beams were cured by water sprinkling twice a day for 14 days, and then left in the laboratory atmosphere until the day of the test. The results of the compression test for concrete cubes on the day of the test gave an average compressive concrete strength of $35 \mathrm{MPa}$ which is higher than the required value. High grade steel bars (36/52) of $10 \mathrm{~mm}$ and $12 \mathrm{~mm}$ were used for the longitudinal reinforcement while mild steel bars (24/36) were used for stirrups with $8 \mathrm{~mm}$ diameter. The tension normal test was performed to evaluate the yield and ultimate strength for the steel used. The results of the yield strength for bars of diameter 8,10 and 12 were $\left(f_{y}=343,497,613\right.$ $\mathrm{N} / \mathrm{mm}^{2}$, respectively) and the ultimate strength were $\left(f_{u}=500,596,710\right.$ $\mathrm{N} / \mathrm{mm}^{2}$, respectively).

\subsection{Test setup}

The test set-up was designed so that pure torsional moment is applied to the tested specimens. The test specimens were simply supported on movable supports specifically made for the test. Loading was applied using a $1000 \mathrm{kN}$ capacity hydraulic jack. The applied vertical load was equally distributed on the two cantilevers at both ends of the beam using a rigid steel I-beam in order to produce torsional load. Two LVDTs were attached to the two ends of the cantilevers to measure the vertical displacement at various loading stages. Figure 4 shows the general arrangement of the test setup for all the specimens.
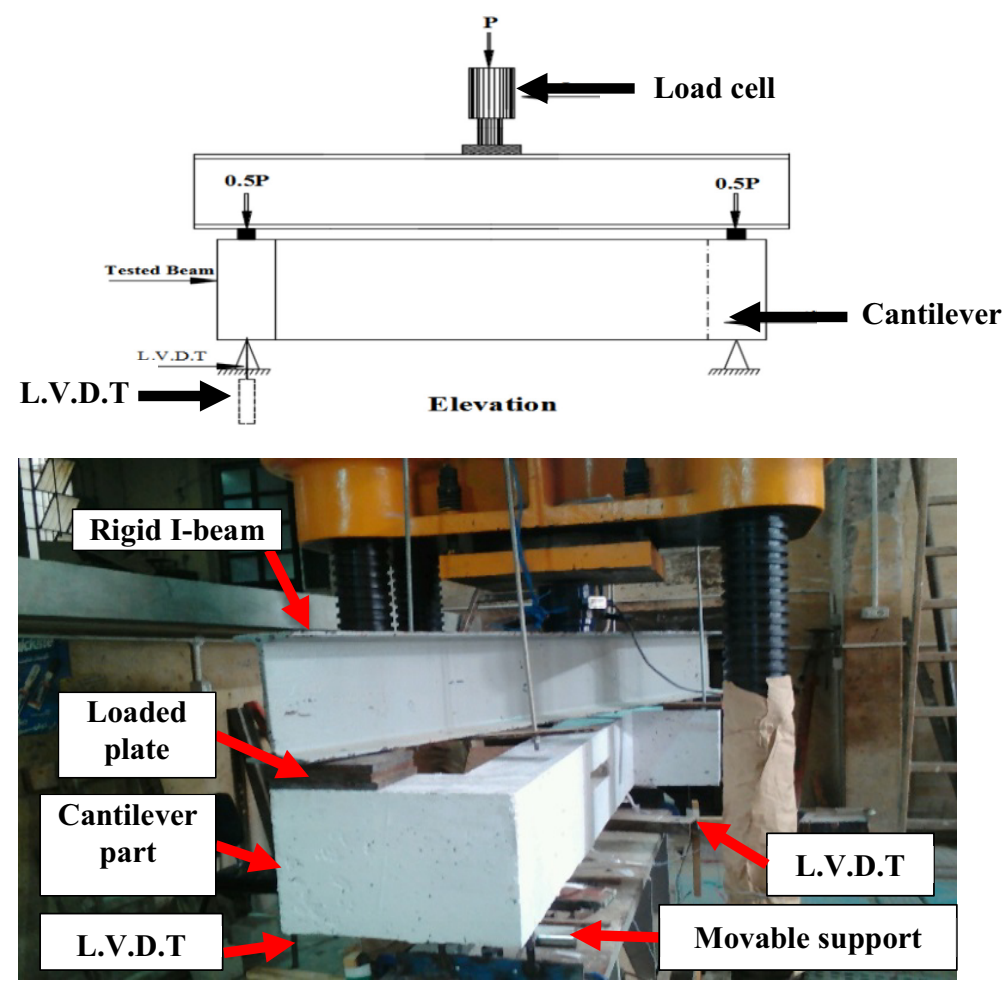

Fig. 4. Arrangement of the test setup for all the tested specimens.

The load on each cantilever was applied in increments. After each increment, all LVDTs readings were recorded. The development and propagation of cracks were marked up to failure. The rotation angle was calculated by dividing the deflections under the two loaded points by the distance between the centerline of the tested beams and loaded point. 
The torque is obtained by multiplying the applied load on the cantilever by the distance between the centerline of tested beams and loaded point.

\section{Analytical study}

In order to assure this study and give the opportunities for future parametric studies, the seven specimens were verified by the non-linear finite element software; ANSYS16 [11]. Eight-node solid brick element SOLID65 was used to model the concrete. SOLID65 is used for 3-D modeling of solids with or without reinforcing bars. The solid is capable of cracking in tension and crushing in compression. The element is defined by eight nodes having three degrees of freedom at each node: translations in the nodal $\mathrm{x}, \mathrm{y}$, and $\mathrm{z}$ directions. The most important aspect of this element is the treatment of nonlinear material properties. The concrete is capable of cracking (in three orthogonal directions), crushing, plastic deformation, and creep. Figure 5 shows the elements used in modeling reinforced concrete using ANSYS16 as well as the compression stress-strain used for concrete. The reinforcement steel was defined using the three dimensional truss element; LINK180 with two nodes; each node also has three degrees of freedom. The mesh used for the specimens as well as the boundary conditions are defined as shown in Figure 6.
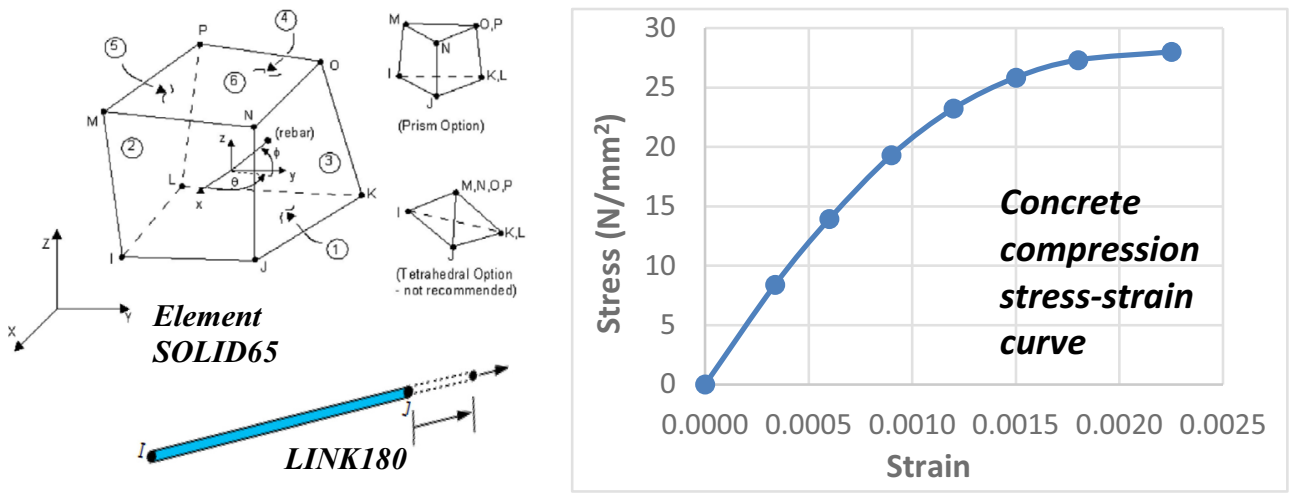

Fig. 5. Modeling of the beams using ANSYS16

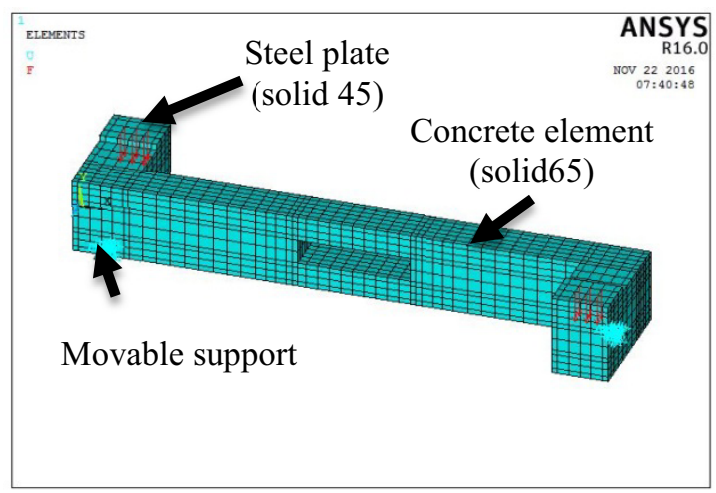

Fig. 6. Mesh used in the analysis 


\section{Results and discussions}

\subsection{Crack patterns}

Figure 7 shows the crack patterns for three of the beams under study as obtained from experiment as well as from the analysis using the ANSYS program. It is noticeable that all the tested beams with openings have the same crack patterns. The first crack appeared at the corner of the opening then at the top chord member. These cracks were inclined with an angle around 45 degrees to the longitudinal axis of the beam. The angle of inclination of the compression diagonals with respect to the beam axis, $\theta$, depends on the ratio of the force carried by the longitudinal reinforcement to that carried by the stirrups [12]. In addition, good agreement can be seen between the FEM analysis using ANSYS16 and the experimental results.

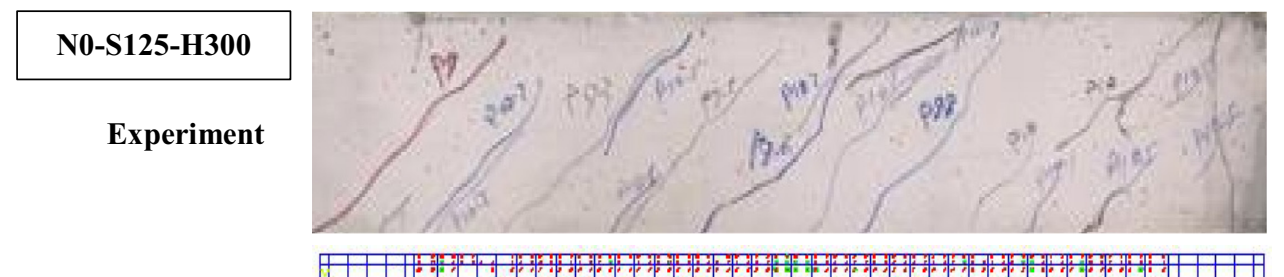

ANSYS
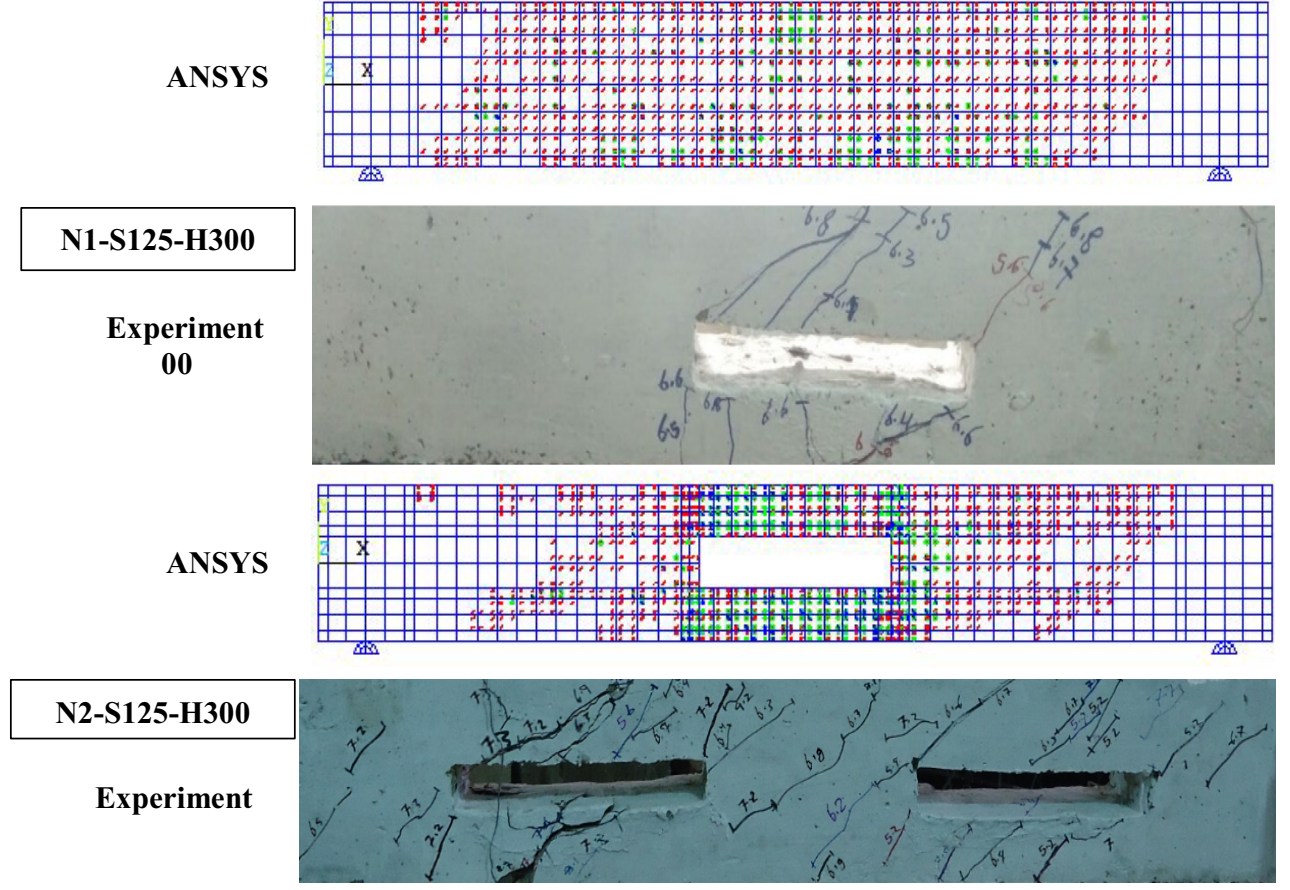

ANSYS

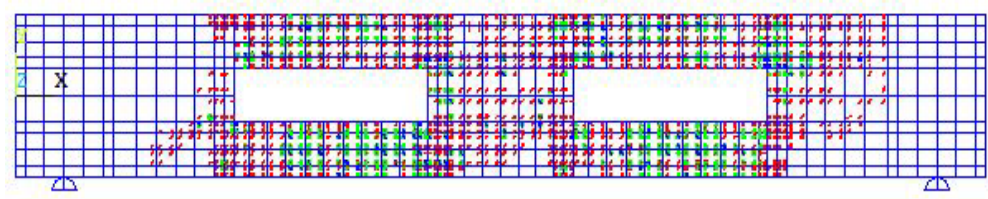

Fig. 7. Analytical and experimental crack patterns for specimens N0-S125-H300, N1-S125-H300 and N2-S125-H300 


\subsection{Torque - Rotation curves}

Comparison between the experimental and analytical outputs of the torque - rotation curves for all specimens can be seen in Figures 8 to 10. The three figures also show the individual effects of the studied parameters. The shapes of the curves are divided into two parts: the first part is linear up to the cracking torque and the second part after cracking which is nonlinear. The slope of the curve decreases with the increase in the torque indicating the post cracking behavior.

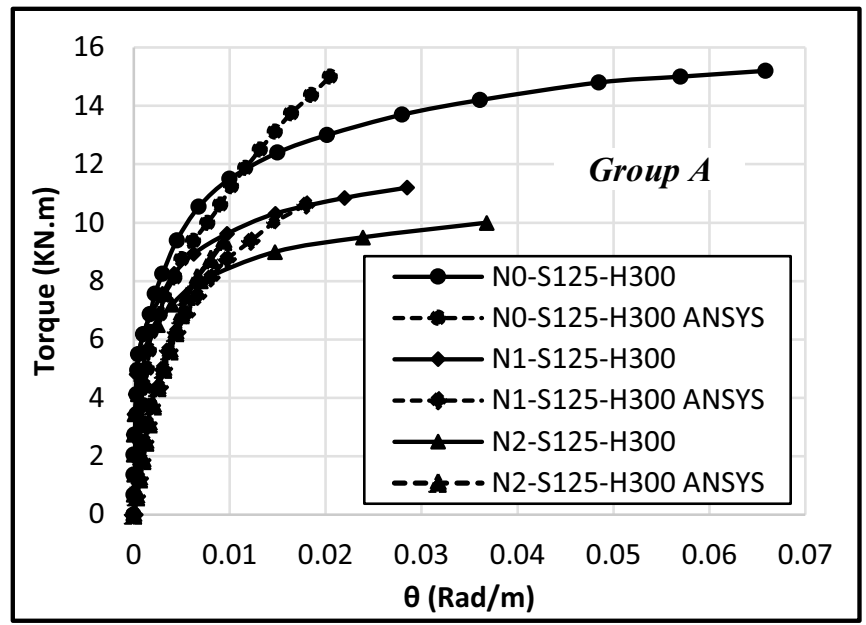

Fig. 8. Torque - rotation curve: Number of opening (Group A).

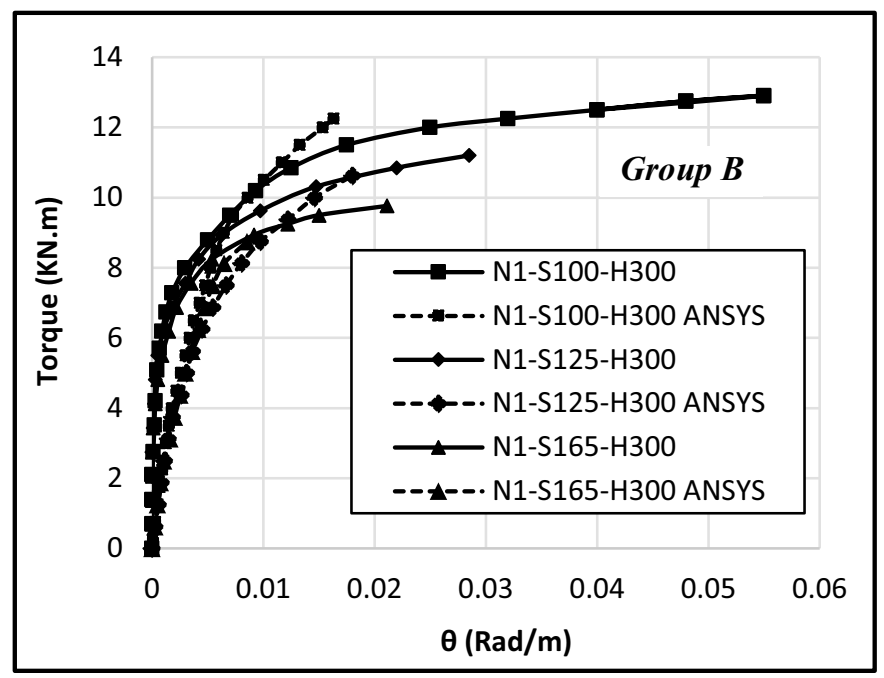

Fig. 9. Torque - rotation curve: Spacing between stirrups (Group B).

In Figure 8, it can be seen that both the ultimate torsional capacity as well as the ductility of the beams are significantly reduced by the presence of openings. Using one opening caused a reduction in the ultimate capacity of about $26 \%$ while the use of two openings caused a reduction of about $34 \%$. Figure 9 shows that decreasing the spacing between the stirrups to $100 \mathrm{~mm}$ caused a significant in improvement in ductility over that with $\mathrm{S}=165 \mathrm{~mm}$ as well as an increase in the ultimate capacity with $32 \%$. Comparing 
specimens, N1-S125-H300 and N1-S100-H300, both beams had one opening and the same beam height but it can be seen that reducing the spacing between the stirrups improved the behavior of the beam. The ultimate capacity was slightly higher but the ultimate angle of rotation was significantly improved almost close to that of the beam with no opening (N0S125-H300).

Increasing the height of the beam from $300 \mathrm{~mm}$ to $400 \mathrm{~mm}$ caused an increase in the ultimate capacity of the beam by $27.7 \%$ but not a very noticeable change in the angle of rotation is recorded as shown in Figure 10. On the whole, a reasonable agreement can be seen between the experimental and the analytical results.

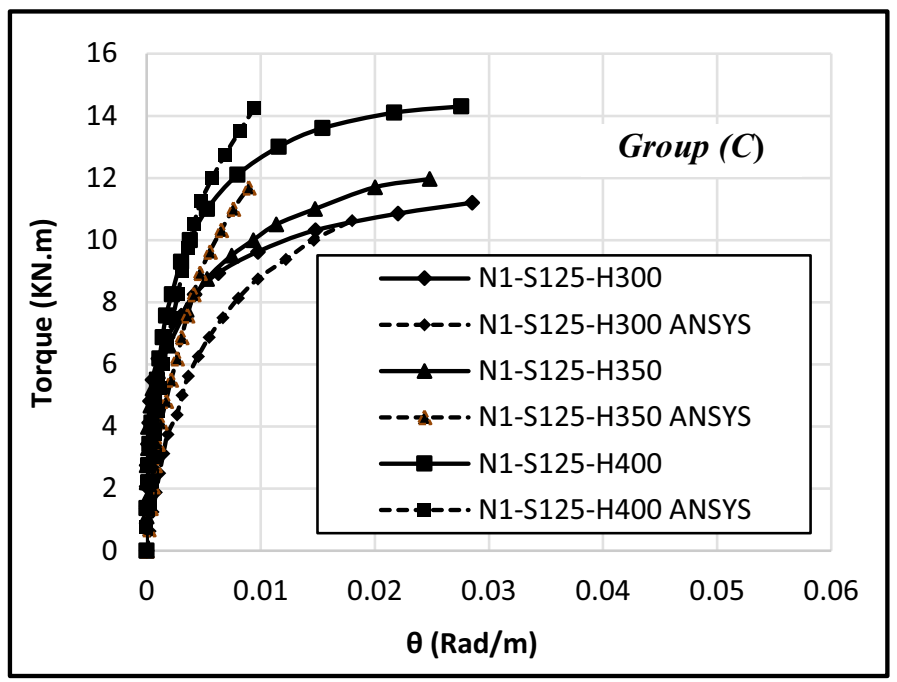

Fig. 10. Torque - rotation curve: Beam height (Group C).

\subsection{Cracking and ultimate torque}

The cracking and ultimate torques $\left(\mathrm{T}_{\mathrm{cr}}, \mathrm{T}_{\mathrm{u}}\right)$ and the corresponding angles of rotation $\left(\Theta_{\mathrm{cr}}\right.$, $\Theta_{\mathrm{u}}$ ) for each specimen as well as a comparison with the ultimate torque obtained from ANSYS are summarized in Table 2. It can be seen that the results of the FEM analysis and the output from the experiments agree well together. The difference between them does not exceed $11 \%$ which is below the acceptable value.

Table 2. Experimental and analytical results of the tested specimens

\begin{tabular}{|c|c|c|c|c|c|c|c|}
\hline \multirow{2}{*}{ ثิ) } & \multirow[b]{2}{*}{ Specimens } & \multicolumn{4}{|c|}{ Experiment } & \multirow{2}{*}{$\begin{array}{c}\text { ANSYS } \\
T_{\mathbf{u}} \\
(\mathbf{k N . m})\end{array}$} & \multirow{2}{*}{$\begin{array}{c}\mathbf{T}_{\mathbf{u} \text { Ansys }} \\
\mathbf{T}_{\mathbf{u}} \operatorname{Exp} \\
(\%)\end{array}$} \\
\hline & & $\begin{array}{c}T_{\text {cr }} \\
(k N . m)\end{array}$ & $\begin{array}{c}\Theta_{\mathrm{cr}} \\
(\mathrm{rad} / \mathrm{m})\end{array}$ & $\begin{array}{c}T_{\mathrm{u}} \\
(\mathrm{kN} \cdot \mathrm{m})\end{array}$ & $\begin{array}{c}\boldsymbol{\Theta}_{\mathbf{u}} \\
(\mathbf{r a d} / \mathbf{m})\end{array}$ & & \\
\hline \multirow{3}{*}{ 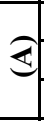 } & N0-S125-H300 & 12.375 & 0.0122 & 15.20 & 0.0658 & 15.00 & 98.68 \\
\hline & N1-S125-H300 & 7.975 & 0.0038 & 11.20 & 0.0285 & 10.63 & 94.86 \\
\hline & N2-S125-H300 & 7.150 & 0.0040 & 10.00 & 0.0367 & 9.38 & 93.75 \\
\hline \multirow{3}{*}{ ๑ิ } & $\mathrm{N} 1-\mathrm{S} 100-\mathrm{H} 300$ & 8.525 & 0.0046 & 12.90 & 0.0550 & 12.25 & 94.96 \\
\hline & N1-S125-H300 & 7.975 & 0.0038 & 11.20 & 0.0285 & 10.63 & 94.86 \\
\hline & N1-S165-H300 & 7.700 & 0.0035 & 9.76 & 0.0211 & 8.75 & 89.93 \\
\hline \multirow{3}{*}{ (2) } & N1-S125-H300 & 7.975 & 0.0038 & 11.20 & 0.0285 & 10.63 & 94.86 \\
\hline & N1-S125-H350 & 9.215 & 0.0074 & 11.96 & 0.0248 & 11.69 & 97.72 \\
\hline & N1-S125-H400 & 9.763 & 0.0093 & 14.30 & 0.0276 & 14.25 & 99.65 \\
\hline
\end{tabular}


Figure 11 shows the results of both cracking and ultimate torque for Group A which studies the effect of the number of openings. While, Figure 12 shows the results for Group B which studies the effect of the spacing between stirrups. Finally, Figure 13 shows the results for Group $\mathrm{C}$ which studies the effect of the height of the beam. As discussed previously in section 4.2 , the three figures show that the three parameters have a significant effect on the behavior of the beams under pure torsion load.

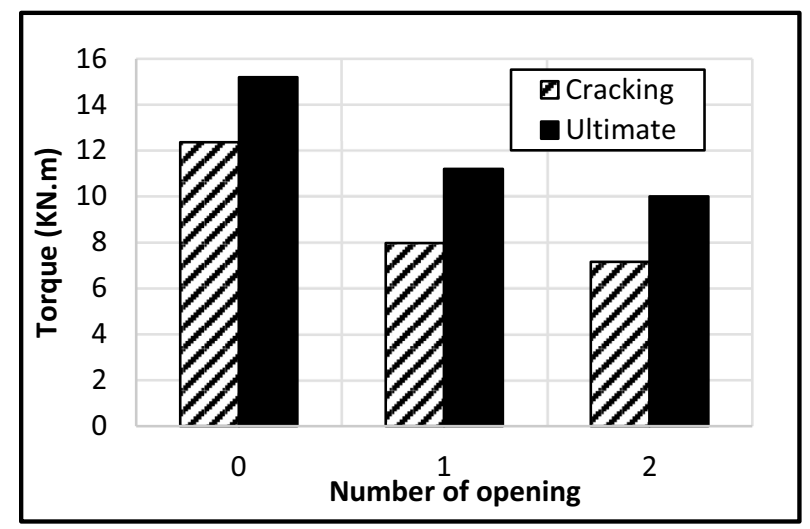

Fig. 11. Cracking and ultimate torque for Group (A)

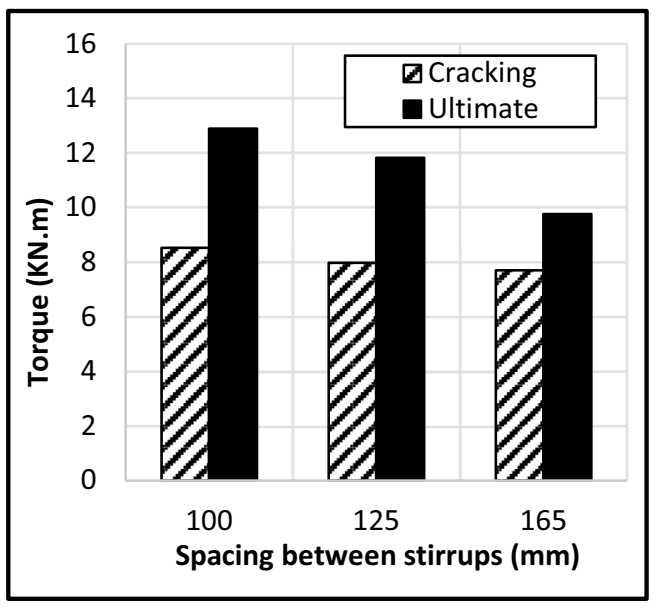

Fig. 12. Cracking and ultimate torque for Group (B)

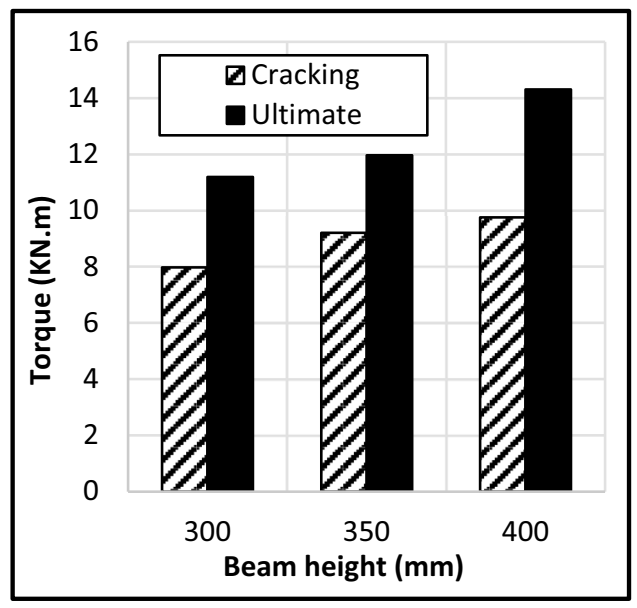

Fig. 13. Cracking and ultimate torque for Group (C)

\section{Conclusions}

Seven reinforced concrete beams were studied in this research. The beams were tested under pure torsion load and then verified using FEM analysis program ANSYS16. The outputs of the experimental program were compared and contrasted with each other as well as with the analytical results and the following conclusions were drawn:

1. The torque-rotation relationship for all the beams under study was linear up to the cracking torque and after that it became nonlinear. The slope of the curves after cracking was very small indicating reduction of beam stiffness after cracking.

2. When the number of openings was increased, the torsional capacity decreased and the ultimate angle of rotation increased. Compared to the control beam, the ultimate torque 
for the beam having one opening and that with two openings was reduced by $26 \%$ and $34 \%$, respectively. While, the cracking torque decreased by $35 \%$ and $42 \%$, respectively.

3. When the spacing between stirrups changed from $165 \mathrm{~mm}$ to $100 \mathrm{~mm}$, the torsional capacity was increased by about $11 \%$ for the cracking torque and $32 \%$ for the ultimate torque.

4. When the beam height was increased by $25 \%$ (from 300 to $400 \mathrm{~mm}$ ), the torsional capacity increased by about $22.4 \%$ for the cracking torque and by about $27.7 \%$ for the ultimate torque.

5. The ultimate angle of rotation increased by $40 \%$ when the spacing between stirrups was decreased by $25 \%$. However, almost no change was seen when the height was increased by $25 \%$.

6. Based on the above, to increase the torsional capacity of a beam that has openings, structural engineers may increase the depth of the beam, and / or decrease the spacing between stirrups around opening. However, the increase in the beam height increases the ultimate torsion capacity with almost no change in the angle of rotation. While, decreasing the spacing between the stirrups cause a noticeable increase in the ultimate capacity but a significant improvement in the ultimate angle of rotation.

7. The analytical results obtained from (ANSYS 16) agree well with the experimental results in terms of crack pattern as well as the ultimate load values which showed differences of no more than about $11 \%$.

Deep gratitude and special thanks are given to Prof. Dr. Magdy E. Kassem for his continuous support and help throughout this research. Without his help, this paper possible would not have been possible.

\section{References}

1. M. A. Mansur, S. K. Ting, S. L. Lee, J. Struct. Eng., 109(8), 1887-1902 (1983)

2. M. A. Mansur, S. K. Ting, S. L. Lee, J. Struct. Eng., 109(8), 1780-1791 (1983)

3. M. El-Badawy, "Torsional Behavior of RC Beams with Web Opening ", MSc. Thesis, Faculty of Engineering, Ain-shames University, Cairo, Egypt (2010)

4. A. Salama, "Behavior of Flange Concrete Beams with Web Opening Under Pure Torsion", MSc. Thesis, Faculty of Engineering, Cairo University, Giza, Egypt (2014)

5. A. A. AKHTARUZZAMAN, ACI Code Torsion Equations Modified for Rectangular Concrete Beams with an Opening, Engineering Sciences, 2(1) (1990)

6. M. A. Mansur, K. H. Tan, "Concrete Beam with Opening Analysis and Design," U.S.: CRC Press LLC, (1999)

7. K. Fawzy, M. M Hashem, A. M. Elnady, Int. J. Eng. and Innovative Technology (IJEIT), Vol. 4, Issue 1, pp.197-204 (2014)

8. M. Venugopal, "Behavior of GFRP Retrofitted Rectangular RC Beams with Small Web Openings under Torsion", Thesis, Department of Civil Engineering, National Institute of Technology, Rourkela, Odisha, India (1990)

9. A. C. Institute, Building Code Requirements for Structural Concrete .manual of concrete practice, USA, Michigan: ACI Committee 318-08, (2008)

10. Egyptian Code for design and Construction of reinforced concrete structural, ECP 2032007 ed., Egypt, (2007)

11. SAS IP, "ANSYS Theory Reference Release 5.6", ANSYS, Inc. Canonsburg, Pennsylvania, USA, (1999)

12. M. Mansur, A. Hasnat, ASCE Journal, Vol. 105, No. STII, pp. 2433-2447 (November 1979) 